\title{
A FORMAÇÃO DO SIGNIFICADO EM VERBOS COGNATOS EM PORTUGUÊS E ESPANHOL: UM ESTUDO GERATIVO- CONSTRUCIONISTA
}

\author{
THE FORMATION OF THE MEANING IN COGNATE VERBS IN PORTUGUESE \\ AND SPANISH: A GENERATIVE-CONSTRUCTIONIST STUDY
}

\author{
Rafaela do Nascimento Melo Aquino ${ }^{1}$ \\ Isabella Lopes Pederneira ${ }^{2}$ \\ Miriam Lemle (in memoriam) ${ }^{3}$
}

\begin{abstract}
RESUMO
Examinando o comportamento sintático e semântico de palavras cognatas em português brasileiro e espanhol, pretendemos contribuir para a compreensão da divisão de tarefas dos submódulos da gramática na interface entre a sintaxe e a semântica. O trabalho considera os modelos construcionistas de gramática da Morfologia Distribuída e Exoesqueletal. A pergunta em pauta é: o que há de constante e o que há de variável nas leituras semânticas dos contextos sintáticos de verbos cognatos nestas duas línguas aparentadas. Selecionamos os pares de verbos mexer/mecer, bater/batir, chegar/llegar para serem examinados em contextos sintáticos bem delimitados. O levantamento comparativo das coincidências e dissidências sintáticas e semânticas entre os verbos nas duas línguas é o conjunto de dados utilizado para esclarecer a natureza da interface sintático-semântica. Neste corpus, houve uma ampla gama de contextos sintáticos aproveitados em todos os verbos, exceto o intransitivo de mecer em espanhol e o transitivo de chegar/llegar em ambas as línguas. Ao fim desse levantamento, ficou constatado que os contextos sintáticos são compartilhados, porém, no aproveitamento semântico, as línguas se diferenciam, resultados que convergem para os modelos construcionistas de Gramática Gerativa.
\end{abstract}

PALAVRAS-CHAVE: Estrutura argumental. Composicionalidade. Teoria Gerativa. Interface sintaxesemântica. Propostas construcionistas.

\begin{abstract}
By examining the syntactic and semantic behavior of cognate words in Brazilian Portuguese and Spanish, we intend to contribute to the understanding of the division of tasks of grammar submodules at the interface between semantics and syntax. The work is guided by the constructionist theories of Distributed Morphology and the Exoskeletal Model. The question at hand is what is constant and what is variable in semantic readings of syntactic contexts of homophonous verbs in these two related languages. We have selected the pairs of mexer/mecer (wiggle), bater/batir (beat), and chegar/llegar
\end{abstract}

\footnotetext{
${ }^{1}$ Universidade Federal do Rio de Janeiro (UFRJ). Doutoranda do Programa de Pós-Graduação em Linguística. Contato: litteramelo@gmail.com.

2 Universidade Federal do Rio de Janeiro (UFRJ). Professora do Departamento de Letras Vernáculas. isabellapederneira@letras.ufrj.br.

${ }^{3}$ Universidade Federal do Rio de Janeiro (UFRJ). Professora do Programa de Pós-Graduação em Linguística. Professora Emérita da UFRJ.
} 
(come) verbs to be examined in well-defined syntactic contexts. The comparative survey of syntactic and semantic coincidences and dissidences between verbs in both languages is the data set used to clarify the nature of the syntactic-semantic interface. In this corpus, there was a wide range of syntactic contexts used in all verbs except the intransitive of mecer in Spanish and the transitive of chegar/llegar in both languages. At the end of this survey, it was found that syntactic contexts are shared, but in semantic uses languages differ, results that converge to the constructionist models of Generative Grammar.

KEYWORDS: Argument structure. Compositionality. Syntax-semantics interface. Generative Theory. Construcionist approaches

\section{Introdução}

As abordagens construcionistas da gramática, Morfologia Distribuída (EMBICK \& NOYER, 2012; HALLE \& MARANTZ, 1992, 1993; HARLEY \& NOYER, 1999) e Exoesqueletal (BORER, 1996, 2005a, b, 2013a, b), nos induziram a estudar o fenômeno da polissemia em verbos cognatos em línguas aparentadas, dada a arquitetura de gramática. A provocação se deve ao fato de que essas abordagens colocam grande peso na formação de significado a partir da sintaxe pura, que, por sua vez, é construída por configurações compostas de átomos funcionais e não de itens lexicais, que comportariam a noção de palavra.

Este é um modo que diverge da gramática gerativa clássica para tratar de fenômenos morfológicos, porque define que a sintaxe é o componente da gramática responsável pela geração de sentenças e também pela geração de sintagmas e palavras. Neste sentido, o significado de palavras, mais especificamente, verbos, é formado a partir da derivação morfossintática desses itens na estrutura argumental que, posteriormente, serão enviados para a interface conceptual para a interpretação de significados. Por exemplo, as configurações possíveis na Gramática Universal (GU) para a estrutura argumental de um verbo são formadas por peças funcionais atômicas abstratas que no decorrer da derivação sintática são selecionadas (numeration) e concatenadas (merge). Após cada fase da derivação sintática, a estrutura formada é enviada para Spell-out e é preenchida com itens de vocabulário providos de traços fonológicos. Além disso, a Enciclopédia fornece significados aos itens formados.

No que diz respeito à contribuição semântica da raiz do verbo, as abordagens construcionistas não apresentam unanimidade quanto ao equilíbrio entre o papel da raiz e o da configuração sintática na formação do significado final das palavras complexas, sintagmas e 
sentenças (HARLEY, 2014). Na MD, em suas propostas iniciais (HALLE; MARANTZ, 1993, 1994; MARANTZ, 1995), assume que as raízes não apresentam traços sintáticos, mas são compostas de informações semânticas ou referenciais e possivelmente morfológicas. É assumido também que, assim como os morfemas funcionais, as raízes recebem informação fonológica tardiamente, no momento de inserção de vocabulário, denominado de Spell-out. $\mathrm{Ou}$ seja, assume-se uma inserção tardia para as raízes. Porém, em propostas mais recentes (EMBICK, 2000; EMBICK; HALLE, 2005; EMBICK; NOYER, 2007), há a defesa da proposta de inserção prévia das raízes (early root insertion). Nessa proposta, apenas os morfemas funcionais recebem expressão fonológica tardiamente. As raízes, por sua vez, são sequências de complexos de traços fonológicos e, em alguns casos, contêm traços diacríticos não fonológicos. Assume-se também que as raízes não contenham traços gramaticais (sintáticossemânticos) e sejam inseridas no início da derivação.

Na teoria Exoesqueletal (BORER, 2005a, 2005b, 2013b), por sua vez, a raiz é um índice fonológico puro, sem conteúdo semântico, selecionado no decorrer da derivação sintática. Nesse sentido, a raiz é entendida como uma referência constante entre todas as ocorrências possíveis de um pacote específico de informação fonológica, como por exemplo, a referência لCORR- nas palavras correr, correria, correnteza etc.

No que diz respeito à relação entre a estrutura sintática e o significado das palavras, uma teoria construcionista como a de Borer (2005a, 2005b, 2013) prevê que a leitura semântica da unidade sintática depende em grande parte do contexto sintático mínimo e não do conteúdo semântico da raiz. Assim sendo, o verbo comer, por exemplo, na sentença transitiva João comeu uma banana, em que o evento expressa uma atividade e é télico, significará ingerir um alimento sólido. Porém, na sentença intransitiva Essa mentira ninguém come, em que o evento é télico, comer significará acreditar em algo. A possibilidade de explicar a formação de significado das palavras a partir de sua formação sintática nos motiva a assumir a proposta construcionista da gramática gerativa como arcabouço teórico deste estudo.

O objetivo específico deste trabalho é estudar, a partir de verbos cognatos em português brasileiro e espanhol, o aspecto sintático-centrismo das propostas construcionistas de gramática gerativa, com dados empíricos na interface sintático-semântica. O trabalho será pautado pelos seguintes objetivos: (i) saber até que ponto podem variar os contextos sintáticos autorizados em cada língua para cada um dos verbos; (ii) averiguar em que medida, em português e espanhol, 
a variação nos contextos sintáticos afeta de modo semelhante a variação nos significados de verbos cognatos.

Os pares de verbos cuja descrição será desenvolvida são mexer/mecer, bater/batir, chegar/llegar em seus diferentes contextos sintáticos. A metodologia do levantamento de dados foi de consulta aos dicionários e introspecção para o português brasileiro e de consulta aos dicionários e buscas no Google para a língua espanhola. A observação desses três pares de verbos mostrou que, em relação ao comportamento sintático, o caso predominante é que todos são inseridos em todas as estruturas sintáticas disponibilizadas pela GU (BORER, 2005b). Apenas no caso de mexer a regência intransitiva não se configurou no espanhol e, no caso de chegar, a estrutura [V DP] não existe em nenhuma dessas duas línguas. Quanto aos aproveitamentos semânticos particulares de cada um dos contextos sintáticos, as divergências entre as duas línguas se acontecem segundo certas subdivisões semânticas que cada verbo apresenta dentro desses contextos sintáticos.

O presente texto se estrutura da seguinte maneira: na Seção 1, apresentamos um breve panorama dos modelos teóricos de gramática que tomamos por base para a análise dos dados; na Seção 2, apresentamos a análise dos pares de verbos mexer/mecer, bater/batir e chegar/llegar; e, na Seção 3, fazemos as considerações finais.

\section{Fundamentação Teórica}

O modelo de gramática aqui assumido parte da hipótese de que o funcionamento do sistema computacional é norteado por três propriedades fundamentais (HARLEY; NOYER, 1999). A primeira delas, sintaxe em toda a derivação, diz respeito ao fato de a sintaxe estar comandando não só a formação de sentenças e sintagmas, mas também de palavras. Assumir que a sintaxe age até no nível mais profundo das sentenças, isto é, na junção de morfemas, influencia diretamente na importância dada ao módulo sintático, pois traz a ele a qualidade gerativa e o coloca na base dos outros módulos da gramática. A segunda propriedade assumida é a Inserção Tardia, que diz respeito ao momento da inserção de item de vocabulário, ou seja, da expressão fonológica de um nó funcional. O item de vocabulário é inserido após a construção do esqueleto sintático, em um processo chamado de Spell-out fonológico. Este é um dos principais pontos em que as propostas lexicalista e a MD divergem, ou seja, em que lugar as informações fonológicas são inseridas no item funcional. A última propriedade assumida, 
Subespecificação de Item de Vocabulário, quer dizer que o item de vocabulário a ser inserido no nó sintático não precisa ser especificado com todos os feixes de traços exigidos na derivação morfológica.

Outro aspecto inovador deste modelo em relação à teoria lexicalista é o fato de decompor o léxico em três listas: a Lista 1 contém somente traços abstratos - ainda sem forma fonológica - como, por exemplo, determinante, pessoa do discurso, número, causa, tempo, relacionador, raiz etc.; a Lista 2 é constituída por itens dotados de matéria-prima fonológica tal como /-o/e /-s/ que correspondem às noções de [MASC.] e [PL], respectivamente; e a Lista 3 apresenta os significados especiais de raízes em seus contextos sintáticos específicos. É por meio desta lista que a relação arbitrária entre som e significado se concretiza. Nesta Lista, está contido também um componente não exclusivamente linguístico a respeito do significado de uma sentença, sintagma ou palavra, como podemos ver em expressões a serem lidas de maneira regular como cachorro em $O$ cachorro da minha avó late muito e também com leitura idiomática, como em dar uma de cachorro magro, em que cachorro magro significa pessoa que deixa a casa que está visitando tão logo tenha se alimentado. Observe a representação do modelo a seguir:

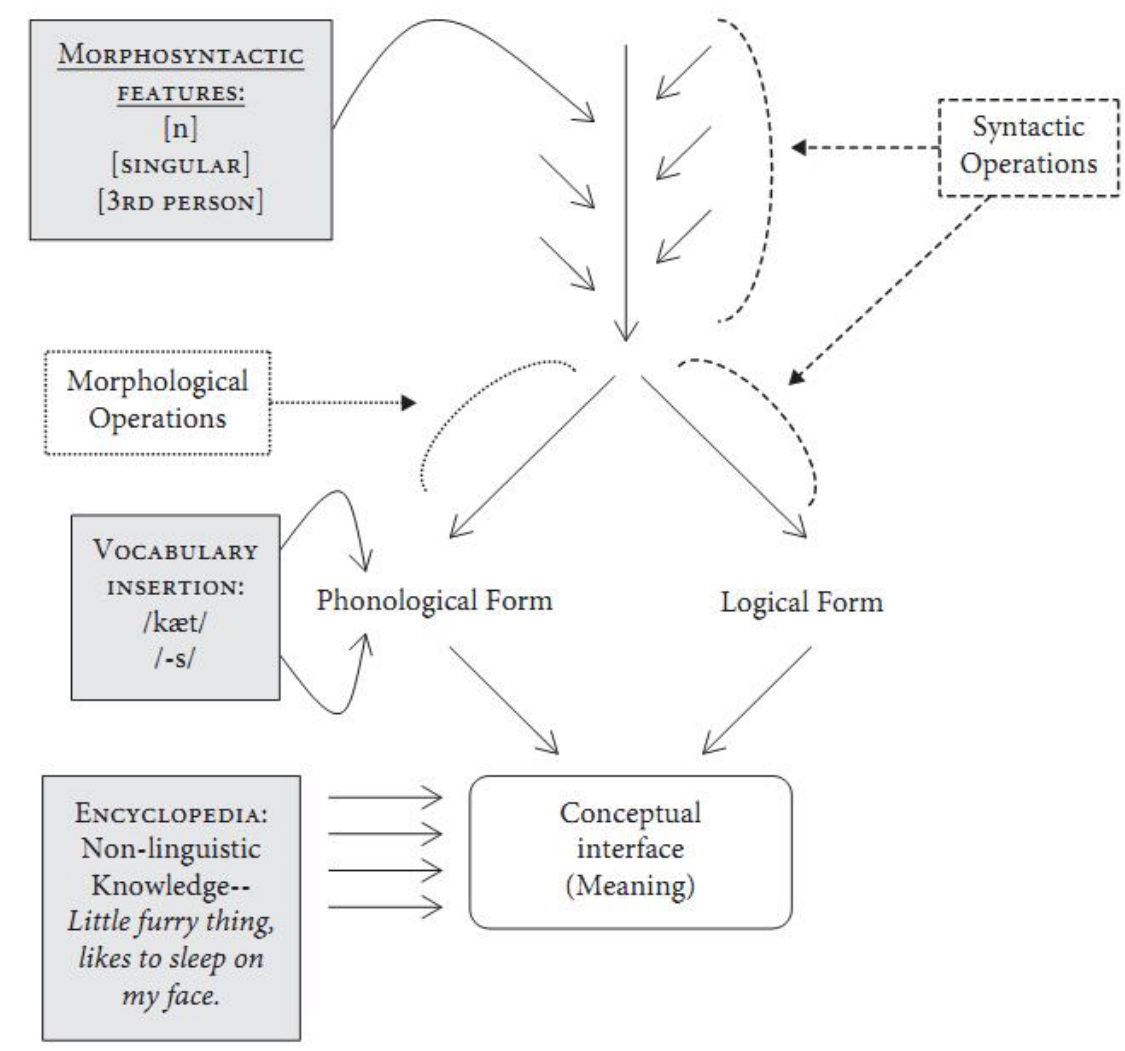

Figura 1: Modelo de gramática da Morfologia Distribuída (Siddiqi, 2009, p. 14). 
No que diz respeito aos verbos, podemos notar que é comum aparecer polissemia, ou seja, mais de um significado para uma mesma forma fonológica. Considerando, por exemplo, os usos do verbo tomar, verificamos que ele pode significar ingerir na sentença Vou tomar um copo d’água e modificar comportamento em Você precisa tomar jeito. Neste artigo, pretendemos desenvolver a questão da idiossincrasia semântica em verbos, relacionando-a com as diferentes estruturas sintáticas. A hipótese aqui adotada para as estruturas sintáticas é de Borer (2003a, 2005a) em que os verbos são encaixados em certas estruturas sintáticas universais, chamadas de templatos, tais como:

Transitivo, Télico:

[eP DP1 [тP DP1 [ASPQ DP2 [vP V]]]] (em duas horas/*por duas horas)
$\mathrm{NOM}$
ACC

Transitivo, Atélico:

[eP DP1 [тP DP1 [FP DP2 [vP V]]]] (*em duas horas/por duas horas)

NOM PRT

\author{
Intransitivo, Télico: \\ [eP DP1 [тр DP1 [ASPQ DP1 [vP V]]]] (em duas horas/*por duas horas) \\ $\mathrm{NOM}$
}

Intransitivo, Atélico:

[EP DP1 [тр DP1 [vp V]]]] (*em duas horas/por duas horas)

NOM

Traduzido de Borer (2003b, p. 6)

No templato em $a$, uma sentença como JoãoDP1 tocou Asa BrancaDP2 em seis minutos tem o DP 1 inserido inicialmente em posição de Spec de Tense Phrase (TP) e depois alçado para Spec de Event Phrase (EP). Já o DP2 é inserido e permanece em posição de Spec de Aspect Phrase (ASPQ), onde recebe leitura télica. No templato em $b$, uma sentença como JoãodP1 tocou Asa BrancaDP2 por duas horas tem o DP1 inserido inicialmente em posição de Spec de TP, que então é alçado para Spec de EP. Já o $\mathrm{DP}_{2}$ é inserido Spec de Functional Phrase (FP), onde recebe leitura atélica. 
No templato em $c$, uma sentença como Asa Branca DPI toca em três minutos tem o $\mathrm{DP}_{1}$ inserido inicialmente em Spec de AspP, sendo depois alçado para Spec de TP e Spec de EP. No templato em $d$, como em $O$ sino da igreja DPI toca por dez minutos, o DP 1 é inserido em Spec de TP e é alçado para Spec de EP. Os exemplos dos diferentes usos do verbo tocar inserido nestes diferentes templatos mostram que há uma regularidade na variedade das relações entre sintaxe e semântica.

Quanto às projeções funcionais presentes nessas estruturas, Borer $\left(2005^{\mathrm{a}}, 2005 \mathrm{~b}, 2013\right)$ propõe a existência de três camadas importantes para a formação da estrutura de evento. É importante compreender que, no entendimento de Borer, a estrutura argumental é resultado das informações de quantidade, em especial telicidade, trazidas pela estrutura de evento. Dessa maneira, a autora postula que a camada Aspe é responsável por atribuir telicidade ao evento. Em sentenças transitivas, nessa camada, o DP em posição de Spec será o argumento interno da estrutura e delimitará o evento, de modo que todo evento télico transitivo deverá ter essa camada projetada (cf. estrutura $a$ e $c$ ). A camada $\mathrm{FP}$ (ou $\mathrm{F}^{\mathrm{SHL}}$ ), por sua vez, é responsável pela atelicidade em sentenças transitivas. Já a camada EP tem como função introduzir o evento a ser denotado pelo verbo.

Em relação ao ponto sintático para a arbitrariedade saussuriana, há divergência entre as propostas da MD e da teoria Exoesqueletal. Marantz (2001), por exemplo, limita a negociação do significado à concatenação da raiz com o primeiro morfema categorizador. Porém, esta fronteira na interface sintaxe-semântica da MD resulta em proporção maior de itens lexicais. Marantz (2013), no entanto, revisita essa proposta e postula que a negociação de significado ocorra no primeiro núcleo de fase $(n, v, a)$ realizado fonologicamente (ou seja, enviado para Spell-out). Desse modo, algumas palavras complexas passam a poder receber novos significados com esse ajuste aos pressupostos da MD.

Porém, Borer (2013 ${ }^{\mathrm{a}}$, p. 84), na teoria Exoesqueletal, postula que as estruturas geradas pelo sistema computacional, após serem enviadas para Spell-out, passam por um mecanismo de busca enciclopédica. Esse mecanismo é responsável por associar a estrutura a um conteúdo conceitual alocado na Enciclopédia. Dessa maneira, estrutura complexas poderão receber novos significados em camadas mais tardias da derivação. Quanto ao ponto sintático para a limitação dessa busca enciclopédica, Borer $\left(2013^{\mathrm{a}}\right.$, p. 85) propõe que uma projeção estendida verbal (entendida, no modelo, como um conjunto de segmentos dominado por um nó funcional verbalizador (e.g. AspP ou T)) pode embarreirar esse mecanismo e, então, a partir dessa 
projeção, a busca não poderá mais ocorrer e o significado da palavra será sempre composicional.

Para maior esclarecimento dessa restrição de localidade, observe a palavra reactionary, da língua inglesa. Essa palavra é formada por três camadas (e.g [N [N[v react] tion] ary]), no entanto, a camada preenchida pelo verbo não é uma projeção estendida verbal, mas uma raiz equivalente a $\mathrm{V}$, por ser complemento de um funtor nominalizador do tipo $\mathrm{C}_{\mathrm{N}[\mathrm{V}]}$ que torna seu complemento equivalente a um verbo. Deste modo, é possível que o conteúdo REACTIONARY recaia na camada nominal mais alta da estrutura, tomando a palavra por completo. Aquino et al. (2018) demonstram essa restrição em português com o nome deverbal plantação. Esse nome apresenta em sua estrutura sintática uma projeção estendida verbal quando denota evento, como exemplificado na sentença A plantação de árvores pelas crianças. Mas, quando denota lugar, em uma sentença como $O$ fogo consumiu toda a plantação, por exemplo, não há essa projeção, possibilitando a mudança de leitura. É importante compreender que, neste modelo, a inserção de conteúdo novo tem caráter cíclico, ou seja, pode ocorrer em cada camada da estrutura enviada para Spell-out, embora essa inserção não seja obrigatória.

Ao explorar este tema acabamos por descobrir que a teoria exoesqueletal se mostra mais satisfatória para a descrição de correspondências semânticas idiossincráticas entre palavras de classes gramaticais diferentes que compartilham a mesma raiz. Por exemplo, na análise da palavra reacionário, que significa politicamente conservador, é impossível derivar esse significado passo a passo a partir de uma regra gramatical que percorra as etapas agir, reagir, reação e reacionário. Esse significado precisará ser atribuído à última etapa morfológica do adjetivo $\left[\left[\left[\mathrm{re}[\mathrm{agir}]_{\mathrm{v}}\right]_{\mathrm{v}} \text { cion }\right]_{\mathrm{n} a ́ r i o}\right]_{\mathrm{adj}}$. Para compor o verbo amarelar com o significado acovardar-se precisamos da estrutura [[amarel $]_{\mathrm{a}}$ ar $]_{\mathrm{v}}$, mais uma vez sem relação semântica com a cor denotada pelo adjetivo amarelo. Na nossa comparação entre verbos cognatos em português e espanhol estamos observando que as mudanças semânticas podem ser imprevisíveis nas raízes quando inseridas em diferentes contextos sintáticos e até mesmo no interior de palavras.

Na próxima seção, mostraremos a análise de três pares de verbos cognatos, a saber: mexer/mecer, bater/batir e chegar/llegar. 


\section{Análise dos verbos}

A tarefa de análise dos verbos será a de perscrutar os contextos sintáticos e de uso de verbos cognatos em português brasileiro e espanhol, de modo a observar os comportamentos regulares, seja do módulo sintático, seja do módulo semântico da gramática.

Partindo do pressuposto de que, na teoria Exoesqueletal, as estruturas sintáticas são templatos, modelos fixos, de uma estrutura eventiva, desenvolvemos, conforme Pederneira $(2015,2016)$, uma proposta que relaciona este modelo ao que Folli e Harley (2004) propuseram ao fixar valores semânticos (sabores) para os vezinhos, utilizando esses valores da Aktionsart nos eventos. Os valores que utilizaremos são os que constam em Duarte et al. (2010).

Tabela 1: Classificação de Duarte et al. (2010) para formação de verbos principais

(Duarte et al., 2010, p. 29)

VCAUSE: [+dynamic], [+ change], [+cause], [+durative], [-instant]

VBECOME: [+dynamic], [+ change], [+cause], [-durative], [-instant]

VDO: [+dynamic], [- change], [-cause], [+durative], [-instant]

$V_{\mathrm{BE}}:$ [-dynamic], [- change], [-cause], [+durative], [-instant]

VDO_INSTANT: [+dynamic], [- change], [-cause], [-durative], [+instant]

A seleção do sujeito será determinada por uma das três peças possíveis: Voz (para sujeito agente), Experienciador ou Causa. Sendo o verbo um predicado complexo de um evento que exige um VP quantificado, este VP quantificado exigirá um agente, um experienciador ou uma causa para tornar-se um evento e, consequentemente, ter seu significado completo atribuído.

Para além desses itens na estrutura, postulam-se as projeções AspQ e $\mathrm{F}^{\text {shl }}$ que são peças, em algumas línguas do mundo, fonologicamente realizadas, e que Borer (2005b) utiliza para, através delas, apontar os aspectos télico ou atélico do complemento do VP. Para saber se o complemento é télico ou atélico, Borer utiliza o teste da preposição in (em) ou for (por), que podem ser aplicados no português ou qualquer outra língua do mundo, naturalmente. A estrutura com a projeção $\mathrm{F}^{\text {shl }}$ determina que a contribuição do complemento do VP tenha um aspecto atélico, enquanto a projeção AspQ determina que a contribuição do complemento do 
VP tenha um aspecto télico. Esta é a diferença que a literatura desenvolve com os nomes de accomplishment e achievement.

Analisaremos, devido aos limites práticos de um artigo, três verbos, tendo em vista o caráter generalista previsto em Gramática Gerativa.

\subsection{O par de verbos mexer/mecer}

Para este par de verbos, apenas em português foi encontrado um uso de mexer no contexto intransitivo. A língua espanhola não utiliza o verbo mecer neste contexto. Observe as sentenças a seguir, (1a) em português e (1b) em espanhol.

(1) a. O cursor do mouse não mexe - português

b. El puntero del mouse no se mueve - espanhol

Outro contexto sintático em que esse verbo é aproveitado é o transitivo. Essa estrutura tem na língua portuguesa uma extensão maior do que a espanhola com o verbo mexer. Veja os exemplos.

(2) a. Ela mexeu a mão

b. Ella movió la mano

(3) a. O cachorro mexeu o rabo

b. El perro movió la cola

(4) a. Ela mexeu a sopa

b. Ella mezcló la sopa

(5) a. O vento mexeu o cabelo dela

b. El viento meció su pelo

(6) a. As chamas estão se mexendo

b. Las llamas se están meciendo

Nas sentenças de (2) a (4), o evento expressa uma atividade e é atélico. Essa natureza aspectual do evento pode ser explicitada pelo teste com a expressão adverbial por X tempo: Ela mexeu a mão por dois minutos. Nesse sentido, a camada aspectual $\mathrm{F}^{\text {shl }}$ é projetada, pois se trata de uma sentença transitiva. Em relação ao tipo de sujeito, essas sentenças apresentam sujeito 
agente, gerado no Spec de VoiceP. Na sentença 6, o evento é atélico e expressa uma causa. Desse modo, o sujeito é causador e é gerado em Spec de CauseP. Já em (6), o evento expressa uma atividade, e o sujeito é um experienciador, gerado em Spec de ExpP. Observe as estruturas das sentenças nas representações arbóreas a seguir:

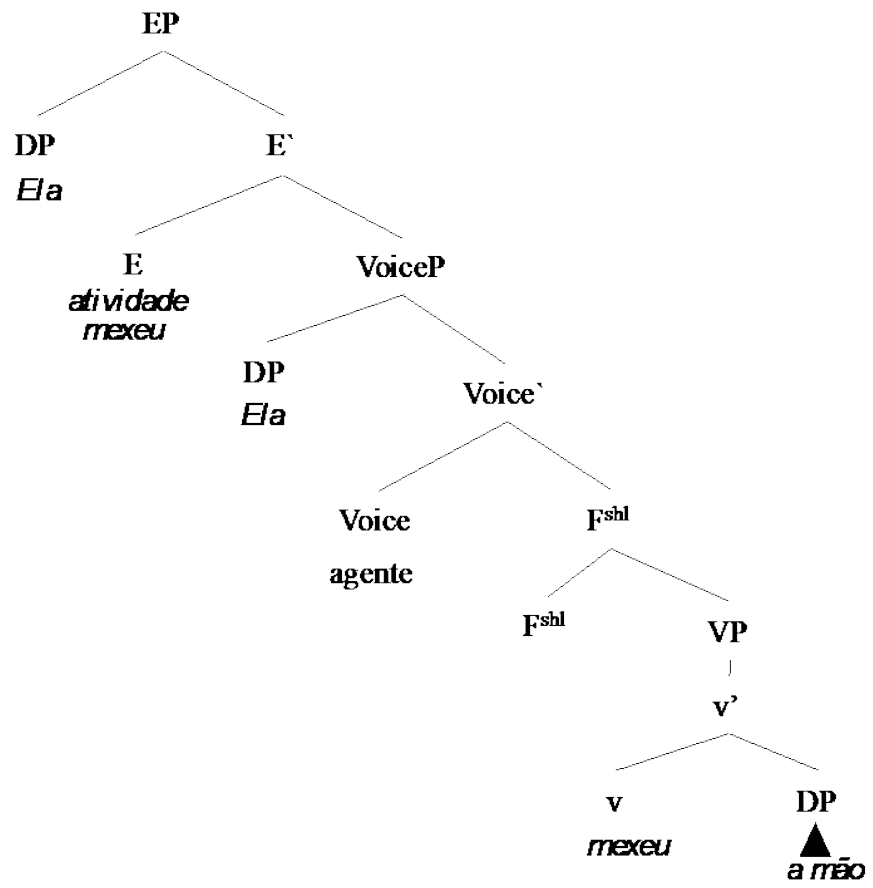

Figura 2: Estrutura transitiva atélica de mexer

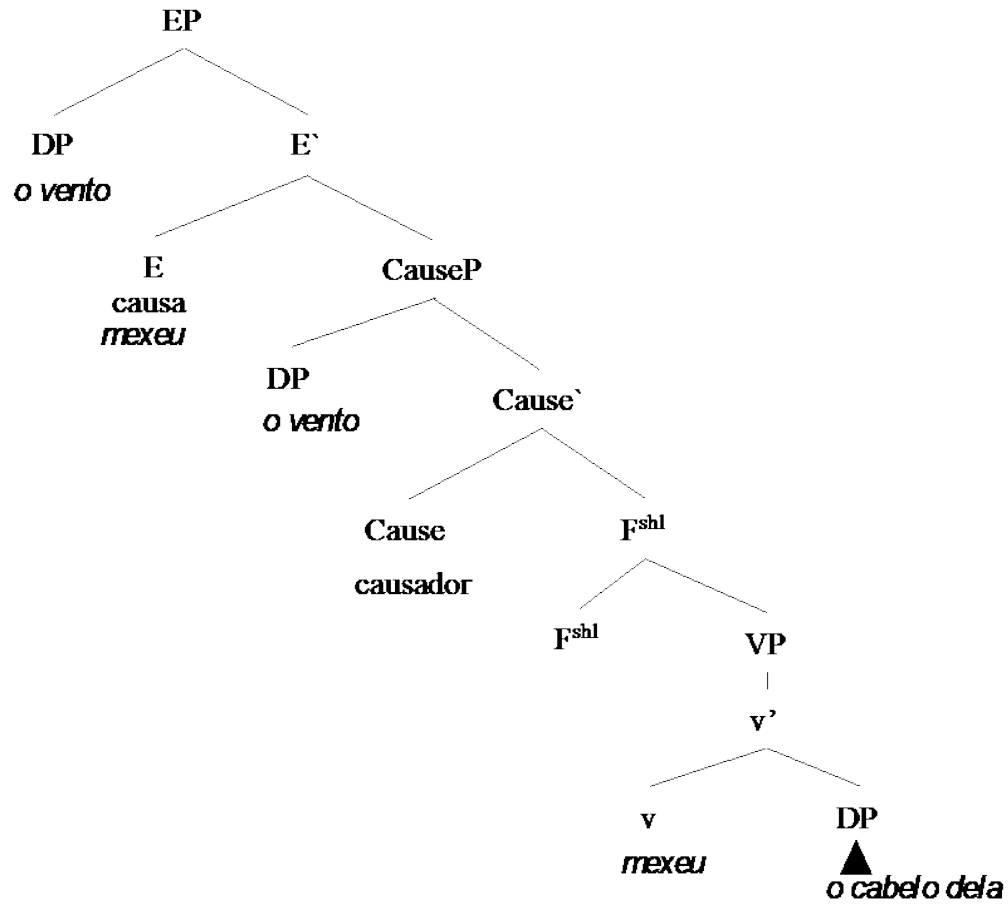

Figura 3: Estrutura transitiva/causa atélica de mexer 


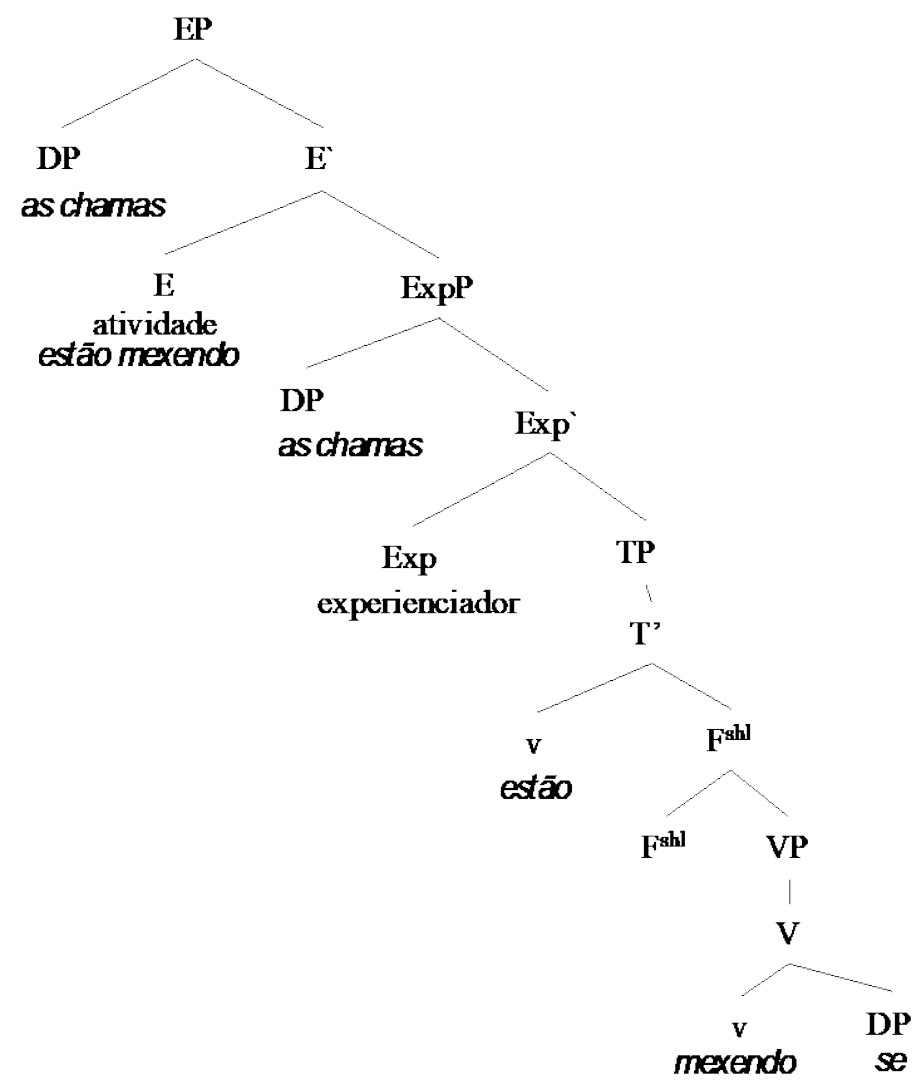

Figura 4: Estrutura transitiva/reflexiva atélica de mexer

Nesses contextos, vemos grande diferença entre as duas línguas. Em português, a posição de objeto direto do sintagma verbal pode ser preenchida por itens que permitam ser movimentados, como mão, rabo, cabelo e, no âmbito culinário, sopa. Nos casos de mão, rabo e cabelo, o verbo mexer denota movimentar, enquanto no caso de sopa, o verbo mexer denota movimento com o intuito de misturar. É interessante observar que a leitura de misturar, neste caso, se justifica pelo fato de que o ato de mexer quando tem a ver com uma matéria pastosa é feito com o objetivo de obter uma mistura homogênea dos ingredientes. Ou seja, mexer, em português, focaliza o momento mais inicial do ato de misturar, enquanto em espanhol é o momento final que é focalizado por mezclar.

Das sentenças apresentadas para o uso de mexer em português, somente (4) tem como tradução para o espanhol o verbo mecer, tendo su pelo preenchendo a posição de objeto. Neste uso de mecer em espanhol, o verbo significa balançar. Este verbo, tanto em português quanto em espanhol, também é usado em uma estrutura reflexiva, como em (6). Nesta estrutura, o verbo descreve o movimento feito pelo sujeito da sentença que neste caso é as chamas. 
Outra estrutura em que o verbo mexer é aproveitado é a com complemento preposicionado: [DP [V PP] vP]. Esta estrutura é usada em ambas as línguas, ainda que o aproveitamento semântico de cada língua seja distinto. Por exemplo, em português, em (7), (8) e (9), o verbo denota respectivamente provocar, arrumar e tocar.

(7) a. Eles mexem com todas as pessoas

b. Ellos se meten con todas las personas

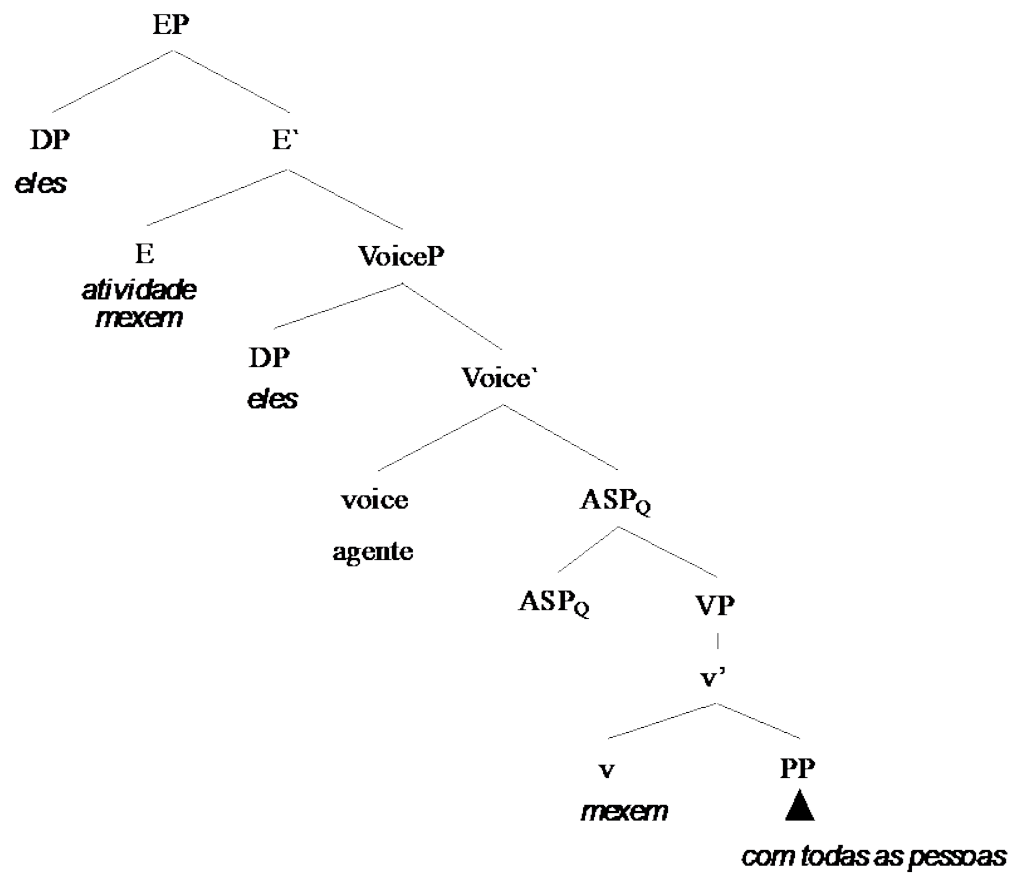

Figura 5: Estrutura com complemento PP télica de mexer

(8) a. Eu vou mexer na sala primeiro, depois vou para a cozinha

b. Yo voy arreglar primero la sala, despues voy a la cocina

(9) a. Não mexa nas minhas coisas

b. No toques mis cosas

Nestes três casos, em espanhol não podemos aproveitar o verbo mecer. Porém, (10) e (11) são gramaticais, com o cognato em espanhol, tendo o verbo mecer os significados balançar e enrolar. Em português, estas sentenças são traduzidas respectivamente como: A mãe balança o berço do bebê e Estão me enrolando.

(10) a. A mãe balança o berço do bebê

b. La madre mece al niño em lacuna 
(11) a. Estão me enrolando

b. Me andan meciendo

Os dados de (7) a (11) mostram que a língua portuguesa tem uma distribuição sintática maior para o verbo mexer do que a língua espanhola para o verbo mecer. Enquanto em português, há um maior aproveitamento das possibilidades sintáticas, em espanhol, a estrutura intransitiva não é usada e as estruturas transitiva e com PP complemento têm uso bem restrito. No que diz respeito à variabilidade semântica deste verbo, convém notar que, em português, o verbo pode denotar movimentar, misturar, tocar e provocar. Já o verbo mecer em espanhol tem significação mais restrita: balançar, na maioria dos casos e enrolar, na expressão me andan meciendo. Esta possibilidade de falta de correspondência semântica entre verbos cognatos e seus significados entre duas línguas proximamente aparentadas nos mostram que dois verbos, indiscutivelmente derivados de uma mesma origem etimológica, podem seguir caminhos distintos em cada língua. Este pequeno levantamento de dados contribui para a hipótese da irrelevância da semântica da raiz, defendida no modelo Exoesqueletal sobretudo. Este é outro dado que nos conduziu a optar por este modelo de gramática, em oposição ao da Morfologia Distribuída.

\subsection{O par de verbos bater/batir}

Um dos contextos sintáticos em que este verbo está inserido é o intransitivo, no qual o evento criado recebe leitura de atividade, e o verbo apresenta uma leitura aspectual atélica, representada pela falta de um nó aspectual. Vamos analisar algumas sentenças.

(12) a. Essa porta bate sempre

b. Esa puerta cierra siempre del golpe 


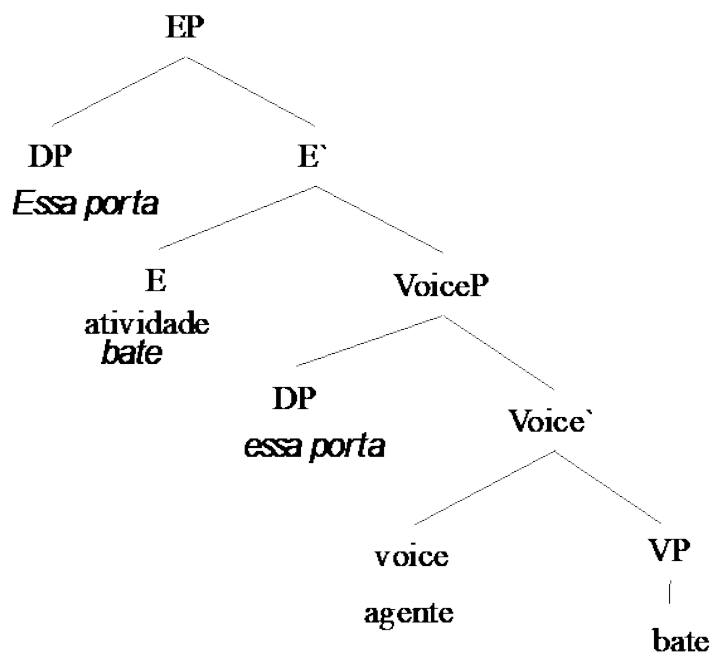

Figura 6: Estrutura intransitiva atélica de bater

(13) a. Algum dia todo carro bate

b. Todos los coches se chocaron

(14) a. O coração do bebê bate rápido

b. El corazón de mi niño late muy rápido

(15) a. Nossas contas não batem

b. Nuestras cuentas no están cuadrando

(16) a. Os tambores de guerra estão batendo

b. Los tambores de guerra están batendo

Nos exemplos (12) a (16), as sentenças apresentam leituras idiossincrásicas. Em (15), a partir da metáfora de um confronto entre duas contas, a leitura de conferir emerge e, em (16), a sentença ganha uma leitura de mensagem. Ao comparar com o espanhol, o verbo cognato batir é inserido na estrutura intransitiva no mesmo contexto da sentença (16a), e nas demais sentenças, os verbos utilizados para a descrição do evento foram, respectivamente, cerrar (del golpe), chocar, latir e cuadrar.

Outra estrutura sintática na qual o verbo bater está inserido é a estrutura transitiva em que o verbo descreve um evento dinâmico. O DP objeto é lido como passando por mudança de estado, e o DP sujeito é inserido através do nó funcional Voice, recebendo papel de agente, conforme a sentença (17), que segue também representada na estrutura arbórea (Figura 7).

\section{(17) a. Ele bateu o ovo \\ b. Él ha batido um huevo}




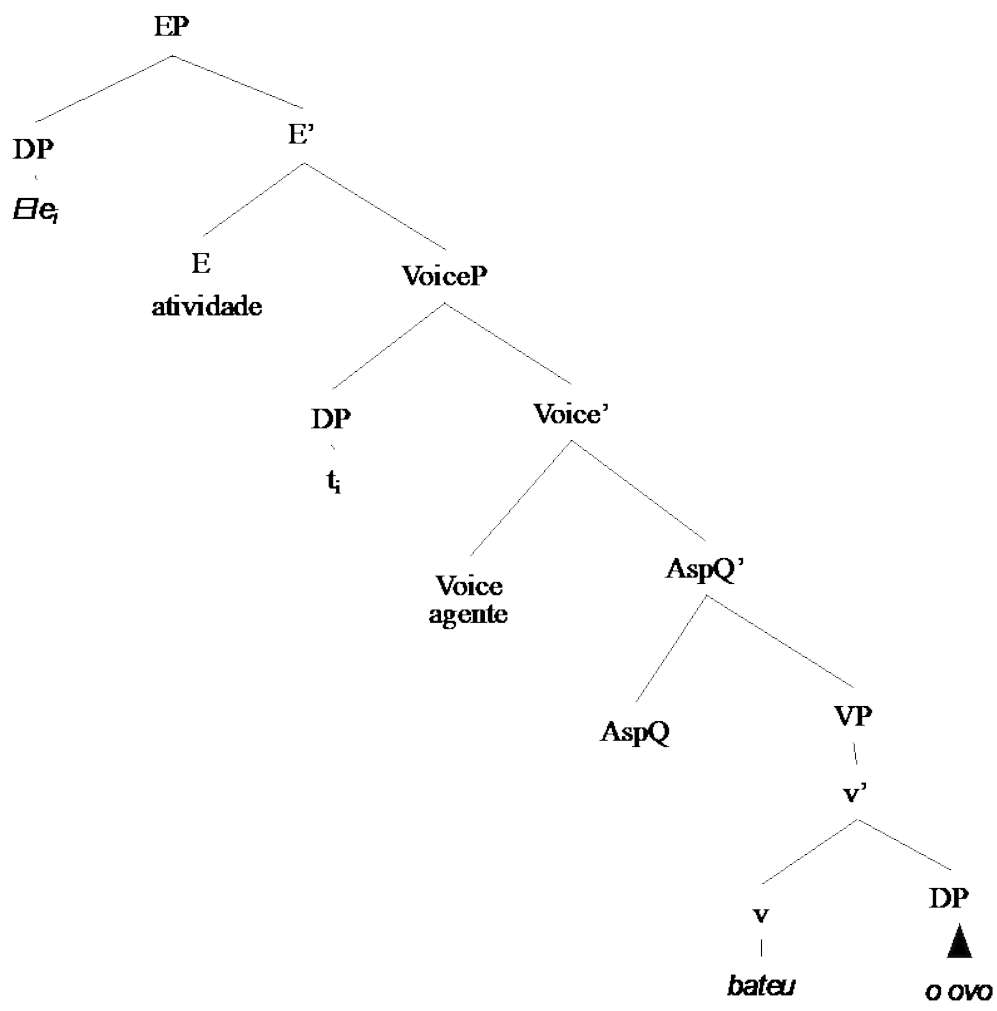

Figura 7: Estrutura transitiva télica de bater

Nas sentenças (18) a (22), o verbo bater tem correspondências sintático-semânticas com o cognato batir em espanhol. Em (18), com o sentido de procurar; em (19), ultrapassar, ir além; em (20), há o movimento de ir para cima e para baixo das asas. Em (21), bater significa vencer, mas o evento descrito em português através da estrutura transitiva Ele bateu o adversário não é descrito em espanhol com a mesma estrutura, tendo al contricante como complemento preposicionado: Él batió al contricante. O verbo bater em espanhol, entretanto, não pode ter o sentido de usar muito uma roupa, como acontece em português, conforme se verifica em (23). Além disso, vemos em (23) que, em espanhol, bater não compõe com o Nome barbilla (queixo) o significando de tremer, arrepiar-se, usando-se então o verbo tiritar.

(18) a. Batemos toda aquela zona

b. Batimos toda aquella zona

(19) a. Ele bateu o recorde olímpico

b. Él batió el récord olímpico

(20) a. O pássaro bate as asas

b. Él pájaro bate las alas 
(21) a. Ele bateu o adversário

b. Él batió al contricante

(22) a. Já estou há três semanas batendo essa blusa

b. Estoy hacetres semanas usando esa blusa

(23) a. Ele estava batendo queixo de frio

b. Él tiritaba de frío

Analisando as estruturas a seguir, vemos que em (24) temos um evento atélico, representado pelo nó aspectual $\mathrm{F}^{\text {shl }}$. Nesta sentença, o argumento apresenta o papel temático de [TEMA], pois é gerado em Spec do PP. Em 25, o evento da sentença é télico, tendo o nó ASPQ projetado. Assim como em (24), o argumento da sentença em (25) é gerado em Spec de PP e recebe papel temático de [TEMA]. Já em (26), o argumento é [AGENTE], o evento é télico e expressa uma atividade, e o complemento do $v$ é um PP.

(24) a. As ondas do mar batem na costa

b. Las olas del mar baten em la costa

(25) a. Uma pedra bateu no para-brisa do carro

b. Um ladrillo se impactó em el parabrisas del coche

(26) a. Anderson Silva bateu em Victor Belford

b. Anderson Silva golpeó Victor Belford

Na sentença em (26), o verbo bater denota dar surra. Em espanhol, somente a sentença (24) aceita o verbo batir. Para descrever o evento em (25) e (26), a língua tem os itens lexicais impactarse e golpear, respectivamente. É importante notar que, tanto em espanhol quanto em português, os verbos cognatos bater e batir aparecem nos mesmos contextos sintáticos (intransitivo, transitivo e em construções com PP), mas o aproveitamento semântico dessas estruturas é maior em português, ou seja, o verbo bater em português é mais rico semanticamente do que o seu cognato em espanhol.

Vejamos as estruturas arbóreas das sentenças (24) a (26): 


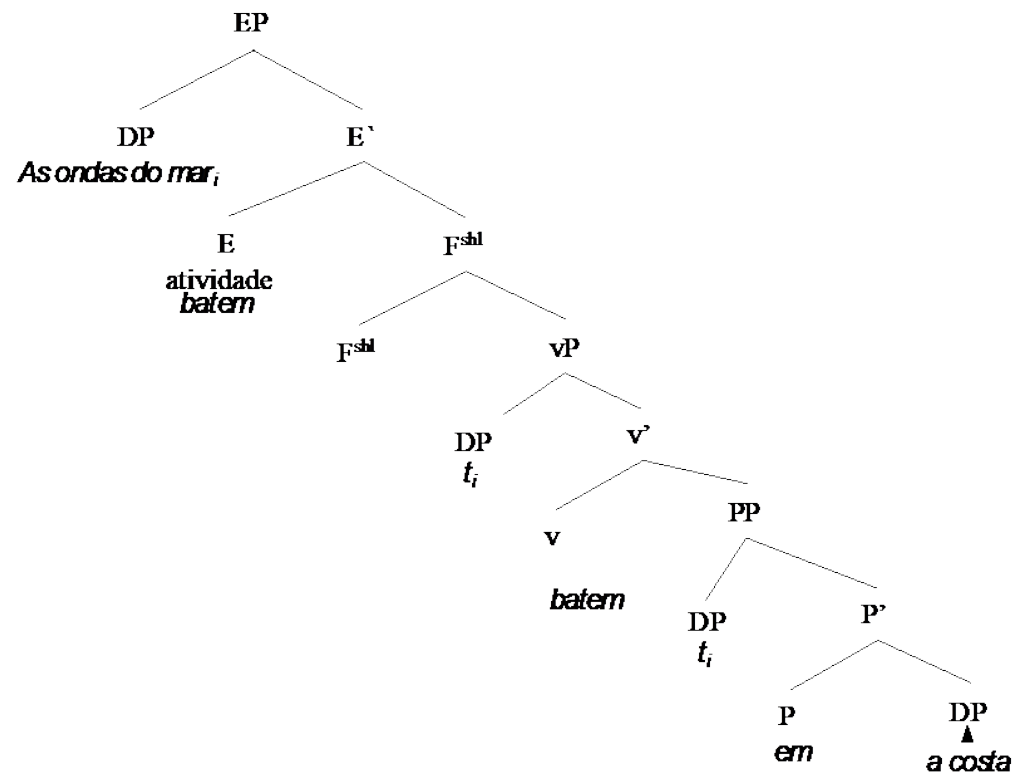

Figura 8: Estrutura com complemento PP atélica de bater

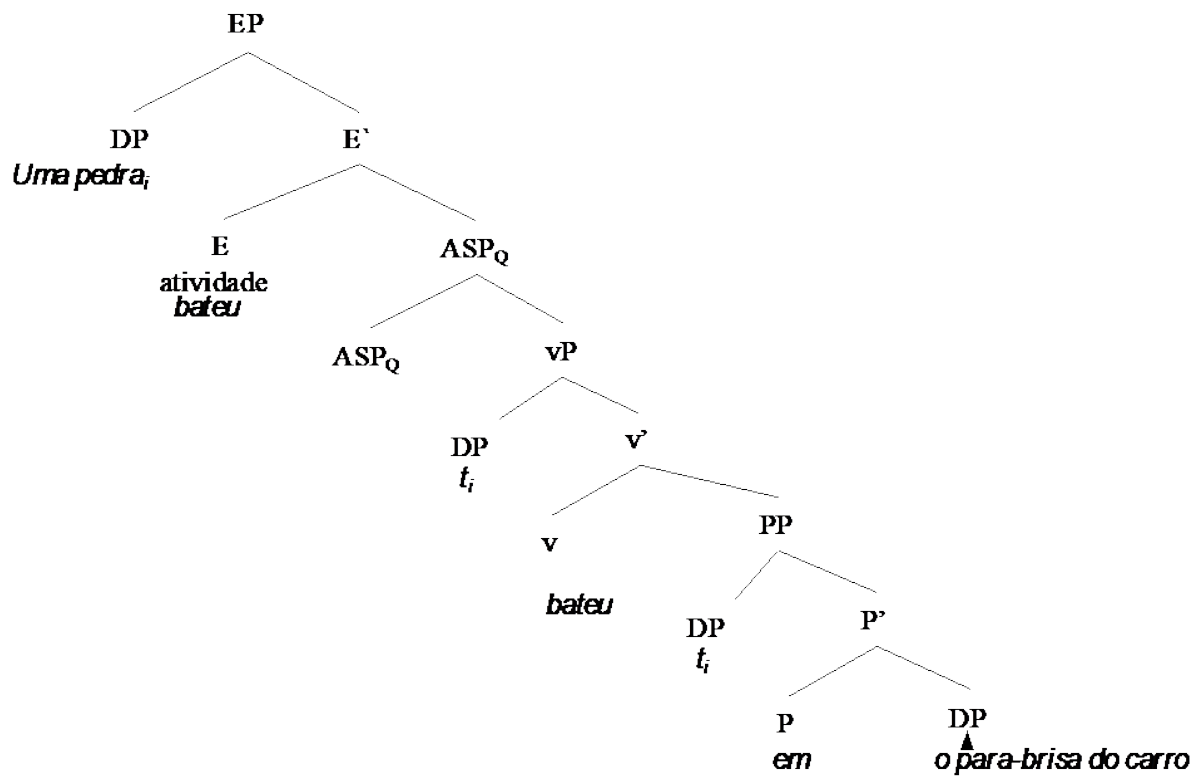

Figura 9: Estrutura com complemento PP télica de bater 


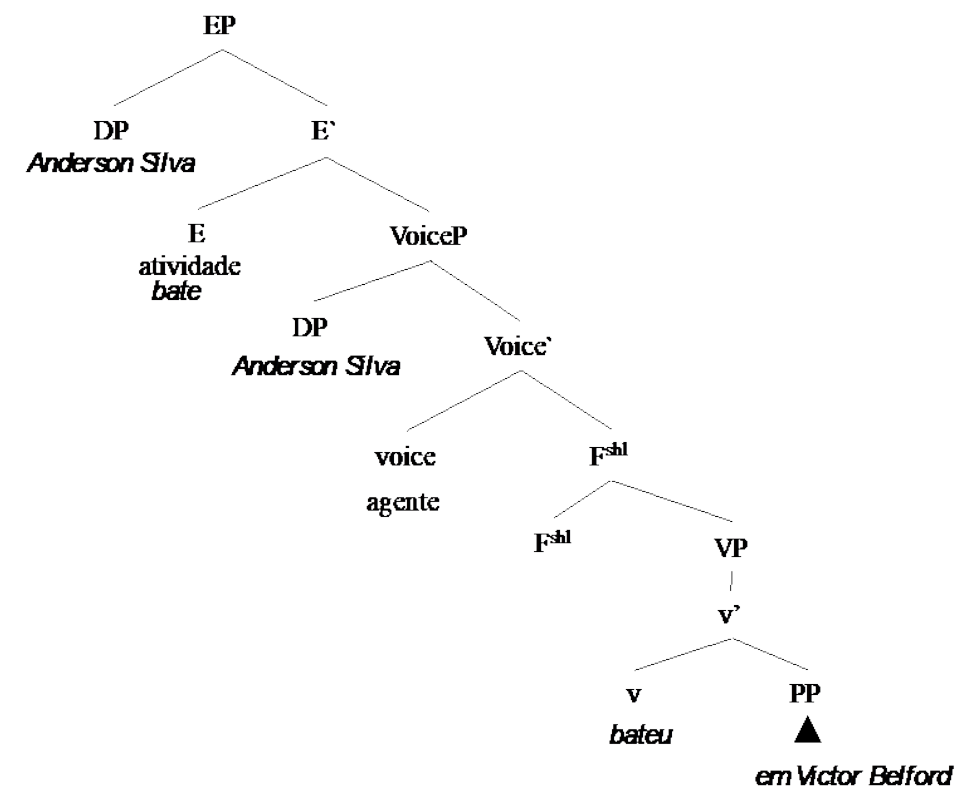

Figura 10: Estrutura agentiva com complemento PP atélica de bater

\subsection{O par de verbos chegar/llegar}

Observando as sentenças (27) e (28) e a representação estrutural arbórea de (27) a seguir, que é igual à de (28), podemos notar que tanto português quanto espanhol admitem o verbo chegar/llegar em construção intransitiva. Nesta estrutura, o vezinho não toma argumento. $\mathrm{O}$ evento denota atividade instantânea, tendo aspecto télico, representado pelo nó $\mathrm{ASP}$.

(27) a. O papai chegou

b. Mi papá llegó

(28) a. O verão chegou

b. El verano llegó 


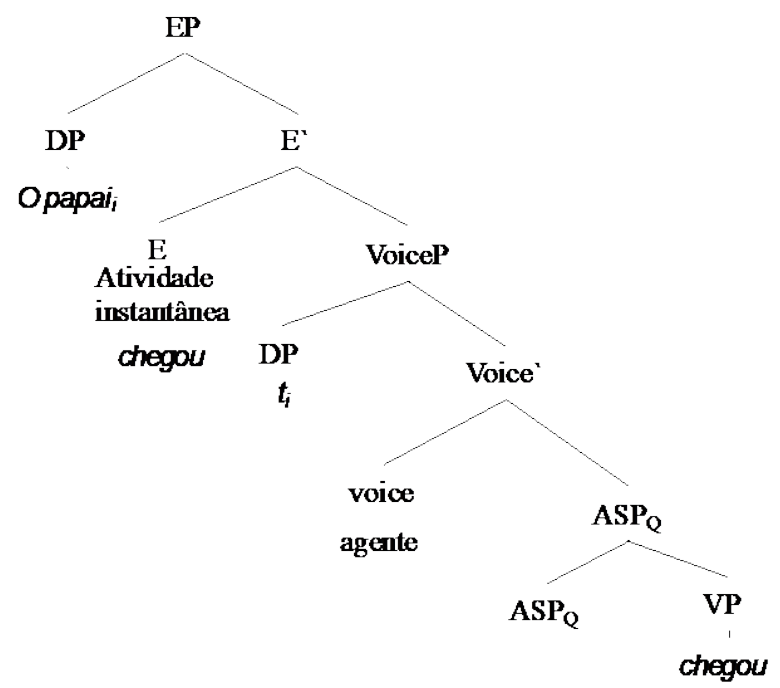

Figura 11: Estrutura intransitiva télica de chegar

Em ambas as línguas, o verbo chegar não é encontrado em estrutura transitiva. No entanto, este verbo é muito empregado na estrutura em que o VP tem um PP como complemento. Em uma construção assim, a preposição relaciona dois DPs por meio de uma estrutura do tipo $\left[\mathrm{DP}_{i}\left[\mathrm{P}^{\mathrm{DP}} \mathrm{DP}_{j}\right]\right.$, em que o $\mathrm{DP}_{i}$ tem leitura de coisa localizada e o $\mathrm{DP}_{j}$ de lugar, sendo que o $\mathrm{DP}_{i}$ Especificador de PP é alçado para Spec de VoiceP. A leitura do verbo nesta estrutura será de movimento no espaço físico. Vamos passar para as sentenças (29) a (31), que têm representação sintática idêntica, tal como se pode verificar a seguir.

(29) a. João chegou ao/no Brasil em 2001

b. Juan llegó al Brasil en 2001

(30) a. Este ônibus chega a/em/até Madri

b. Este autobus llega a Madrid

(31) a. Meu pai chegou a/em casa cedo

b. Mi padre llegó a casa muy temprano 


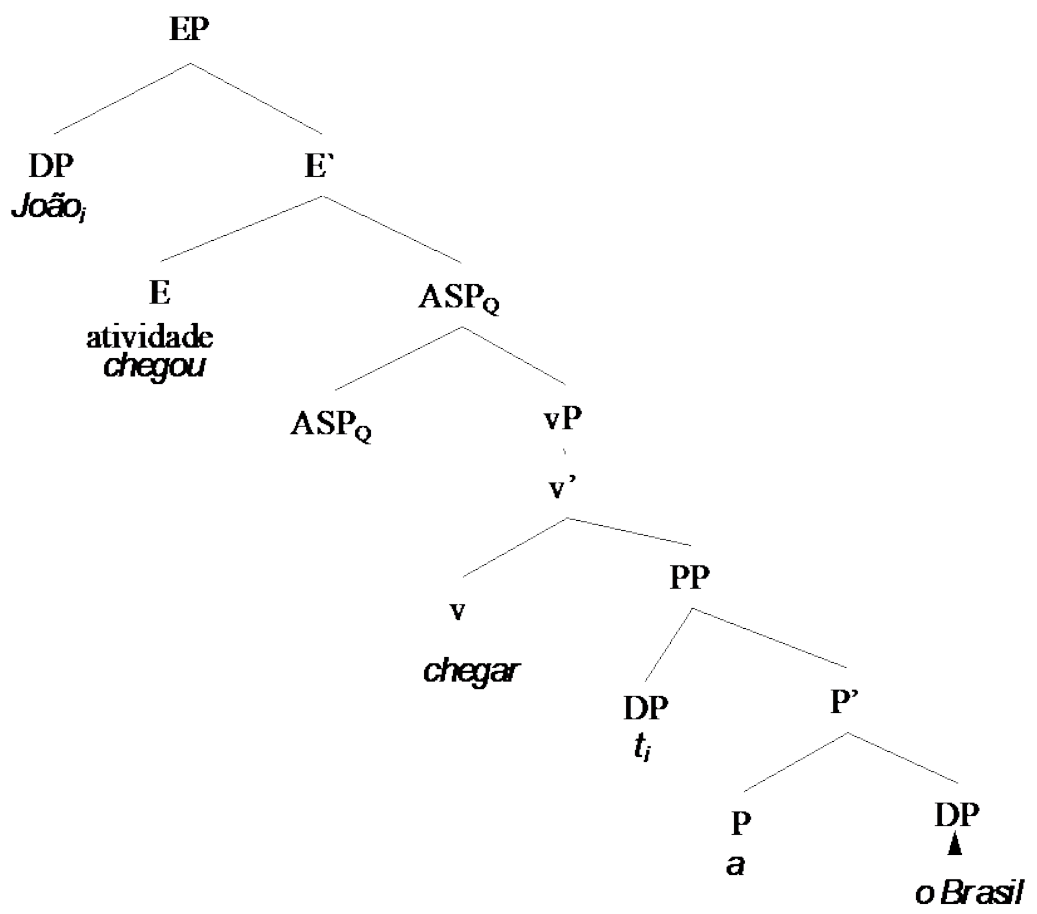

Figura 12: Estrutura com complemento PP télica de chegar

Nesta estrutura de (29), se vê que as preposições usadas com o verbo chegar são $a$, até e em. Quando a preposição $a$ é o núcleo do PP, algumas alterações semânticas surgem de acordo a semântica de seu complemento. Como se pode ver nas sentenças em (32) e (33), se o complemento da preposição nomear um status social, profissional ou acadêmico, visto em (32), a leitura da construção será a de um estágio dentro de uma carreira ou na sociedade o qual constitui um avanço, como em (32).Se o complemento de chegar a for um verbo no infinitivo, como em (33), a leitura será a de um ponto limite inesperado do evento.

(32) a. Ele chegou a general

b. Él llegó a general

(33) a. Ele chegou a desmaiar

b. Él llegó a desmayar

No contexto gramatical da construção chegar a, a posição sintática de complemento é adotada para introduzir um evento pragmaticamente relevante. Vale notar que chegar a, a partir de sua semântica regular, abre a possibilidade de seu complemento receber a leitura pragmática de resultado surpreendente, tal como em (33). 
Outra estrutura possível com o verbo chegar é a representada em (34). Esta estrutura se distingue das dos exemplos (32) e (33), pois os Especificadores do vP e do PP não são iguais e o papel temático do sujeito não provém da posição de $S p e c$ do PP, mas da posição de Spec do nó Voice. Neste contexto estrutural, não há correspondência do verbo chegar em português com o verbo llegar em espanhol, pois em português o verbo chegar ganha a leitura de fazer ir.

(34) a. Ele chegou a cadeira para trás

b. Él echó la silla para atrás

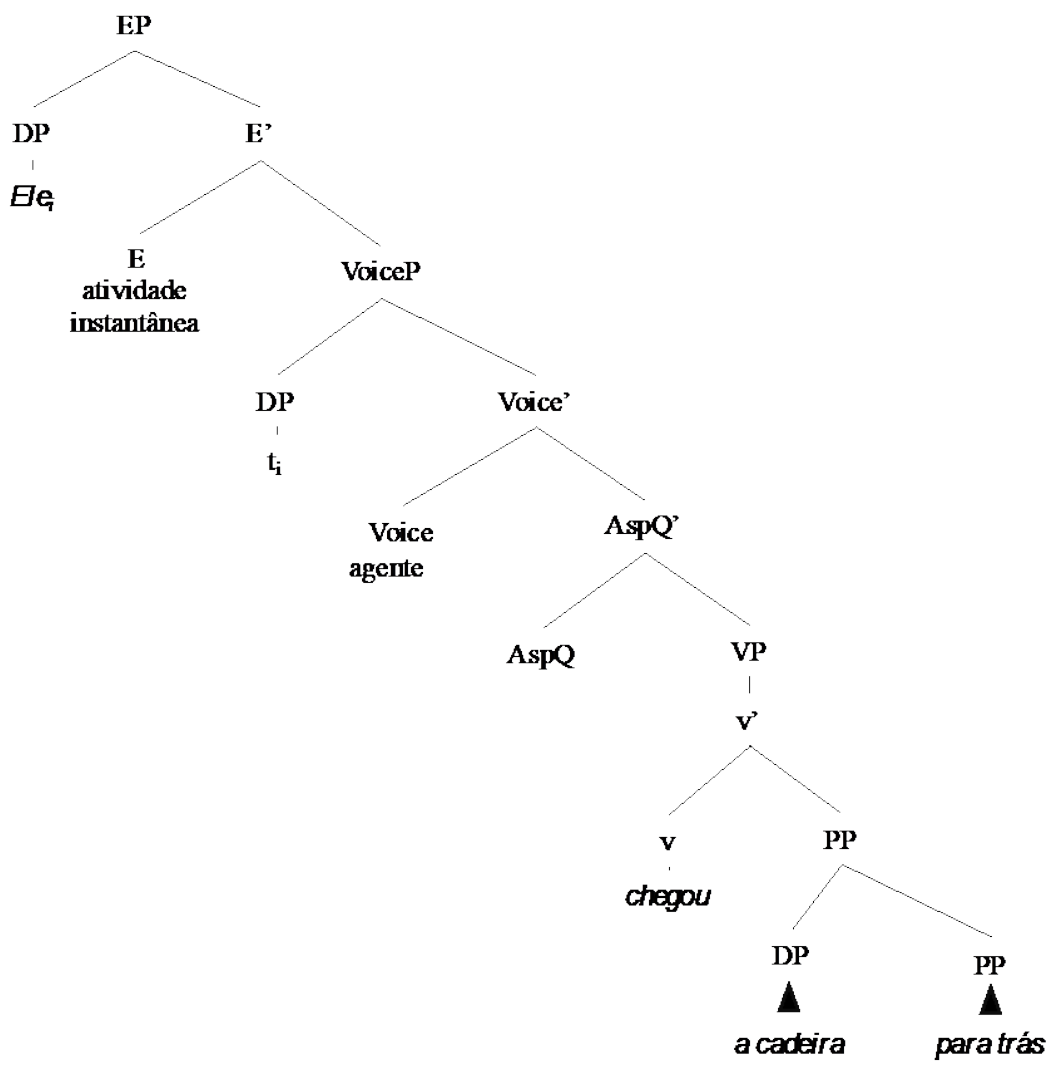

Figura 13: Estrutura agentiva com complemento PP de chegar

Outra possibilidade de uso deste verbo é com sujeito impessoal e complemento introduzido pela preposição de, conforme representado a seguir:

(35) a. Chega de falar/batata

b. Basta de hablar 
Em (35), Verbo ou Nome que complementa a preposição de expressa um pedido de suspensão da ação. Esse uso no português pode ser abreviado para somente o verbo chegar (Chega!), e neste caso fica implícita no discurso qual a atividade a ser suspensa. Em espanhol, esta construção não é descrita com o verbo llegar (chegar), mas com bastar. Essa construção é um caso curioso de uma idiomatização sintaticamente restrita à sentença matriz, tempo presente e sujeito nulo de $3^{\text {a }}$ pessoa do singular. Portanto, seria agramatical uma sentença como Quando o gerente da loja chegou, chegamos de conversar.

A análise do verbo chegar leva à constatação de que há uma grande polissemia para esta forma. O verbo pode denotar: deslocamento para, mudança de status para, ponto limite de evento e pedido de suspensão da ação. É interessante notar como em cada contexto sintático pode eclodir um significado diferente, o que sustenta a proposta apresentada pela teoria exoesqueletal de que é possível uma mesma forma verbal, segundo o contexto sintático, variar o seu significado. Ao confrontar com o espanhol, encontramos grande correspondência semântica entre chegar e llegar nas estruturas estudadas, excetuando o apresentado em (34) e (35).

Como pudemos ver, o mecanismo sintático, com os nós funcionais, pode podem originar estruturas específicas. A razão por que podemos afirmar que a configuração sintática é responsável por diferentes significados é em grande parte devido ao fato de que o verbo polissêmico precisa estar em uma construção eventiva (atividade, atividade instantânea, estado, mudança, causa). Além disso, o tipo de sujeito é restrito, trazendo importantes contribuições para o significado da estrutura argumental. Os nós funcionais VoiceP, CauserP ou ExpP selecionam o tipo de sujeito que será incorporado à estrutura.

O modelo Exoesqueletal de Gramática Gerativa parece ter ferramentas melhores e mais econômicas para lidar com dados de polissemia de línguas. É possível analisar de forma coerente, também por meio das representações com árvores. A teoria projecionista é pouco econômica ao dar estatuto central para a semântica com a teoria dos papéis temáticos. Quanto às teorias construcionistas em geral, estas parecem lidar melhor com a polissemia, ao extrair da sintaxe e da morfologia a possibilidade exaustiva de geração de componentes da gramática. Entre os modelos da Morfologia Distribuída e o da Exoesqueletal, a segunda opção mostra-se eficaz ao dar possibilidade de separar as categorias de verbos através do armazenamento de estruturas de templatos de evento adotados como estruturas típicas. Deste modo, além de economizarmos na quantidade de entradas lexicais, ainda é possível diminuir o número de 
ajustes pós-sintáticos, como type-shiftings, pois estariam resolvidos antecipadamente na sintaxe.

Por fim, é importante notar que a antecipação das classes da Aktionsart para a sintaxe não é meramente uma troca desproposital de posições da semântica para a sintaxe. O principal objetivo é restringir as possibilidades de significados. Além disso, os dados das línguas confirmam que uma palavra não pode significar qualquer coisa, embora sua capacidade de reanálise e idiomatizações seja grande.

\section{Considerações finais}

A observação destes três pares de verbos cognatos em português e espanhol (mexermecer; bater-batir e chegar-llegar) nos fez considerar que, do ponto de vista morfológico/sintático, eles se assemelham, pois o que predomina é que todos aparecem em todas as estruturas sintáticas verificadas na análise, à exceção de mecer, sem construção intransitiva, e de chegar e llegar, que não possuem a estrutura [V DP]. Quanto aos aproveitamentos semânticos particulares de cada um dos contextos sintáticos, as divergências entre as duas línguas se dão segundo certas subdivisões semânticas que cada verbo apresenta dentro das estruturas sintáticas estudadas. Na medida em que essas estruturas em que o verbo está inserido se distinguem, os conceitos vinculados a ele podem ser modificados, confirmando a hipótese da teoria exoesqueletal de que a apropriação de conceitos novos a um vocábulo é dependente da estrutura sintática.

Para resumir, este confronto entre as duas línguas nos permite notar o êxito da abordagem exoesqueletal na compreensão de que microcontextos sintáticos podem arcar com diferenças de uso de verbos cognatos. Este achado corrobora ainda a hipótese de que a raiz não apresenta conteúdo semântico intrínseco, mas que o significado dos verbos surge a partir da sua interação na estrutura argumental.

Considerando a confirmação empírica das hipóteses propostas, podemos explicar, por exemplo, dados etimológicos de mudança de significado de verbos do latim para línguas românicas sem termos a necessidade de reformular dados morfológicos. Neste sentido, o fato de que um verbo como aggregare, do latim, possuía o significado de grex (rebanho) em sua estrutura e de que, em português, este dado nominal não é consciente para os falantes vem a ser 
resultado apenas da inserção do item lexical na estrutura sintática, que é uma das responsáveis pela formação do significado em cada sistema linguístico.

\section{Referências}

AQUINO, R.N.M. Encontros e desencontros semânticos em palavras cognatas nas línguas portuguesa e espanhola. 2016. 110 f. Dissertação (Mestrado em Linguística). Programa de PósGraduação em Linguística. Universidade Federal do Rio de Janeiro, Rio de Janeiro, 2016.

AQUINO, R.N.M, PEDERNEIRA, I.L, LEMLE, M. A relação raiz e estrutura sintática na semântica da formação de palavras no português brasileiro e espanhol. Revista da ANPOLL.Vol.1 Num.45, 2018

BORER, Hagit. Exo-skeletal vs. Endo-skeletal Explanations: Syntactic Projections and the Lexicon, in. M. Polinsky and J. Moore (eds.) The Nature of Explanation. Chicago: Chicago University Press (distributed by CSLI). 2003a.

. The Grammar Machine, in A. Alexiadou, E. Anagnostopoulou and M. Everaert, eds. The Unaccusative Puzzle, Oxford University Press. 2003b.

Structuring Sense Volume I: In Name Only. 1. ed. Nova Iorque: Oxford Univeristy Press, 2005a.

. Structuring sense Volume II: The normal course of events. 1. ed. Nova Iorque: Oxford Univeristy Press, 2005b. 417 p.

. Derived nominals and the domain of content. Lingua p. 1-33 , 2013a.

. Structuring Sense Volume III: Taking Form. 1. ed. Nova Iorque: Oxford Univeristy Press, 2013b. 704 p. . Syntax and Morphology: An Overview. p. 1-61, 1996.

DUARTE, I.; GONÇALVES, A.; MIGUEL, M.; MENDES, A.; HENDRICKX, I.; OLIVEIRA, F.; CUNHA, L. F.; SILVA, F.; SILVANO, P. Light verbs features in European Portuguese. Proceesings of Verb 2010 - The identification and Represatation of Verb Features, Pisa 4-5, Università di Pisa, 2010, p. 27-31.

EMBICK, David; NOYER, Rolf. Distributed Morphology and the Syntax-Morphology Interface. The Oxford Handbook of Linguistic Interfaces. [S.1: s.n.], 2012.

FOLLI, Rafaela; HARLEY, Heidi. Flavors of v: consuming results in Italian and English. In: SLABAKOVA, R. and KEMOCHINKY, P. (eds.), Aspectual Inquiries. Dordrecht: Kluwer, 2004; p. 95-120.

HALLE, Morris; MARANTZ, Alec. Some key features of Distributed Morphology. MIT Working Papers in Linguistics. [S.1: s.n.], 1992.

. Distributed Morphology and the Pieces of Inflection. In K. Hale and S. J. Keyser (eds) The View from Building 20: Essays in Linguistics in Honor of Sylvain Bromberger. 111-176, Cambridge, MA: MIT Press, 1993.

HARLEY, Heidi; NOYER, Rolf. Distributed Morphology. GLOT 4.4 n. April, p. 3-9 , 1999. 
HARLEY, Heidi. On the identity of roots. Theoretical Linguistics, 40(3-4), 225-276, 2014.

MARANTZ, Alec. No escape from syntax: don't try morphological analysis in the privacy of your own lexicon, in A. Dimitriadis, L. Siegel et al., eds. University of Pennsylvania Working Papers in Linguistics, vol. 4.2, Proceedings of the 21st Annual Penn Linguistics Colloquium, p. 201-225, 1997.

PEDERNEIRA, I.L. Implicações teóricas dos verbos leves para o estudo de estrutura argumental. Tese (Doutorado em Linguística) - Programa de Pós-graduação em Linguística Faculdade de Letras, UFRJ, Rio de Janeiro, 2015.

Implicações teóricas dos verbos leves para o estudo de estrutura argumental. Veredas - Revista de Estudos Linguísticos Veredas atemática. p. 160-182 - PPG Linguística/UFJF - Juiz de Fora, 2016

KRATZER, Angelika. Severing the external argument from its verb. In: Rooryck, J., Zaring, L. (Eds.), Phrase Structure and the Lexicon. Kluwer Academic Publishers, Dordrecht, p. 109137, 1996. 